\title{
Colonic perforation and acute abdomen complicating antibiotic-associated pseudomembranous colitis
}

\author{
LARRY JAY FEINMAN, DO \\ STANLEY D. KOLMAN, DO \\ ANTHONY A. MINISSALE, DO, FACOS \\ VIVIAN M. BARSKY, DO, FACOS
}

\begin{abstract}
Pseudomembranous colitis (PMC) is an acute bacterial infection of the colon that is caused by the organism Clostridium difficile. In most cases, PMC occurs when antibiotic therapy suppresses normal flora in the colon, which allows overgrowth of the $C$ difficile bacteria. The severity of the disease can range from benign and self-limiting to fulminant (toxic megacolon). Only rarely does colonic perforation occur secondary to PMC. The authors report three cases of perforation in elderly women. Each patient was admitted in a toxic and septic condition, and, despite aggressive surgery, each patient died. The etiology, manifestations, diagnosis, and treatment of PMC also are discussed.
\end{abstract}

Pseudomembranous colitis (PMC) results from a colonic infection with the organism Clostridium difficile, which can overgrow in the colon when the normal flora are suppressed by antibiotic administration. There have, however, been reports of PMC occurring in patients without histories of antibiotic use. ${ }^{1}$

While an asymptomatic carriage state of $C$ difficile does exist, most patients who have this bacteria demonstrable in their fecal flora manifest PMC. $^{2}$ The disease can range from benign, selflimiting, mild diarrhea to severe, bloody diarrhea, cramps, and fever; it can progress further to toxic megacolon with perforation and sepsis.

The first reported case of PMC was in 1893 by Finney, who described it as a complication in a patient who had undergone gastroenterostomy. For quite a while, the etiology remained clouded. Then, in 1943, Hambre and associates demonstrated that penicillin could cause fatal hemorrhagic cecitis in guinea pigs. Soon it was shown that a variety of antibiotics could cause this lesion, and when it was seen that Staphylococcus aureus was cultured from the feces of patients with PMC, and that oral van- comycin was therapeutic, the disease was termed staphylococcal enteritis. $^{3}$

Later, it was shown that $S$ aureus commonly overgrows in the colons of patients taking broad-spectrum antibiotics and that most of these patients do not develop PMC. This cast serious doubt on the role played by $S$ aureus in PMC. In addition, it was demonstrated that this "enteritis" did not affect the entire intestinal tract, but only the colon, and that it ended abruptly at the ileocecal valve. Therefore, the disease was renamed antibiotic-associated pseudomembranous colitis. ${ }^{4}$

In 1975 , it was shown that the disease could be passed from an infected animal to a healthy one via transrectal inoculation. The toxic substance could be filtered through a $0.02-\mu$ filter, which suggested a toxin or microbial product as the etiologic agent, rather than the complete bacteria. It was then demonstrated that the toxin could be neutralized by Clostridium sordellii antitoxin, thereby suggesting a clostridial toxin. Stool culturing demonstrated $C$ difficile. ${ }^{5}$

Most cases of pseudomembranous colitis are selflimiting or treatable with oral medications. Very rarely, the disease progresses to a fulminant state, which is characterized by toxic megacolon, perforation, and acute abdomen. A review ${ }^{6}$ in 1983 found only 13 cases of documented toxic megacolon. In 1984 , Snooks and coworkers ${ }^{7}$ reported the first case of PMC presenting as perforation.

In this paper, we report three cases of pseudomembranous colitis; all three presented with acute abdomen secondary to colonic perforation. All three were admitted in extremis-toxic and septic, with acute abdominal findings. The working diagnosis in all three cases was ischemic colitis, and the actual diagnosis was not made until laparotomy.

\section{Report of cases}

Case 1

A 69-year-old woman was admitted on May 3, 1984, with complaints of fever, diarrhea, and worsening abdominal 
pain. The diarrhea had been present for approximately two weeks, but it had become worse and associated with abdominal pain during the last three days.

The patient said that she had had a 10 -to-15 pound weight loss over the past month. Her medical history was significant for steroid therapy for Addison's disease, hypertension, and cerebrovascular accident. She had completed a course of antibiotic therapy prior to development of her symptoms.

On physical examination, she was alert and oriented and in mild distress. The heart was regular, and the lungs were clear. The neck was supple and without masses or jugular venous distention. The abdomen was distended and tympanitic with high-pitched bowel sounds. There was guarding in the right lower quadrant, with rebound tenderness. Extremity examination was unremarkable.

Roentgenographs of the chest and abdomen were unremarkable, as were abdominal and pelvis echograms.

Laboratory results of significance included a white blood cell count of $20,000 / \mathrm{cu} \mathrm{mm}$ and a differential shift of $37 \%$ band forms.

After fluid resuscitation in the intensive care unit, the patient was transferred to the operating room for laparotomy. The abdomen contained a large, free, intraperitoneal abscess, and the cecum was perforated. The cecal serosa was inflamed acutely. Resection of the right colon and ileotransverse colostomy were performed.

Postoperatively, the patient developed multiple medical problems, including respiratory failure, renal failure, and sepsis. Unresponsive to treatment, she died on May 13.

Pathologic study demonstrated classic PMC (Figs 13 ). In addition, stool specimens collected in the emergency department were positive for $C$ difficile and also for toxin.

\section{Case 2}

After she was found unresponsive and diaphoretic in her nursing home, a 68-year-old woman was admitted on Aug 30,1985 . Her medical history included adrenal in-

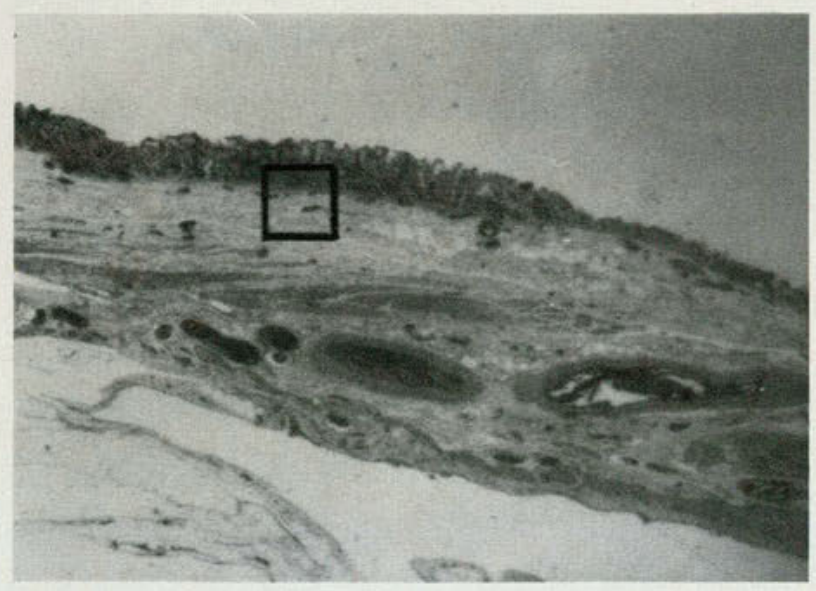

Fig 1. Section through involved area of cecum in case 1 (hematoxylin and eosin stain, $\times 18$ magnification).

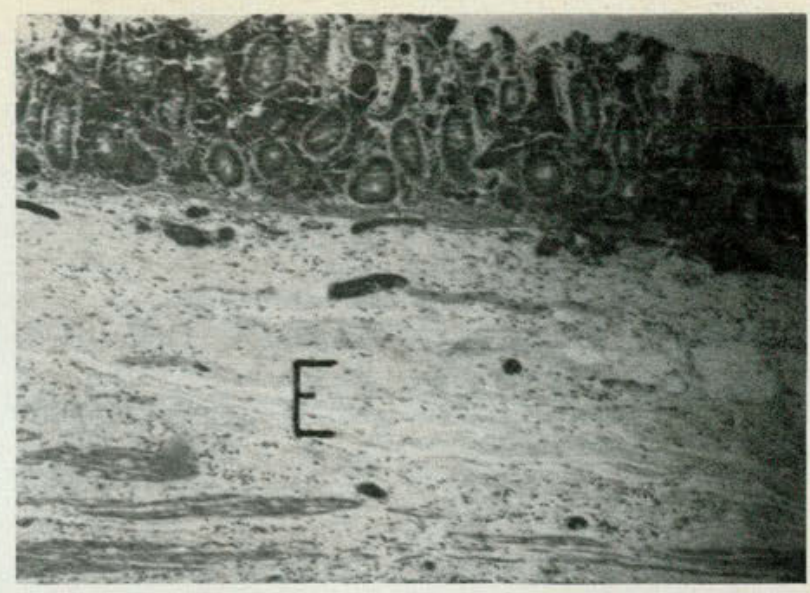

Fig 2. Enlargement of area in Fig 1 (case 1). There is extensive submucosal edema (E) and mucosal valvular congestion (hematoxylin and eosin stain, $\times 400$ magnification).

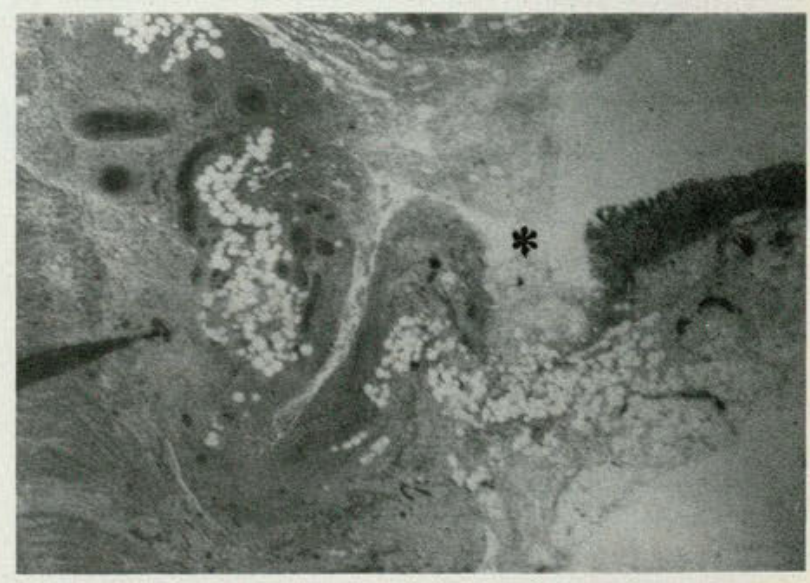

Fig 3. Site of perforation (asterisk) in case 1. There is ulceration into the submucosa, with an involved adjacent mucosal area (hematoxylin and eosin stain, $\times 18$ magnification).

sufficiency, insulin-dependent diabetes mellitus, and chronic obstructive pulmonary disease.

In the emergency department, the patient's blood pressure was $80 / 40 \mathrm{~mm} \mathrm{Hg}$. She had a grand mal seizure shortly after arrival. She was found to be theophylline toxic (theophylline level of $48 \mathrm{mg} / \mathrm{mL}$; normal, 10-20), and antitoxicity treatment was begun immediately.

Once the postictal state wore off, the patient became alert but not oriented, which was her usual mental status. Examination of the heart and lungs was normal. Abdominal examination revealed multiple scars and prior operations, the natures of which were not known. There was guarding and rebound tenderness in the right lower quadrant. Rectal examination revealed no masses, while the stool specimen was heme positive.

Significant laboratory results included a white blood cell count of $23,300 / \mathrm{cu} \mathrm{mm}$, with a differential shift of $23 \%$ band forms. The hematocrit value was $31.8 \%$ and the serum potassium level was $3.1 \mathrm{mEq} / \mathrm{L}$. Chest roentgenographs were unremarkable; abdominal films showed gastrectasia and cecal distention to $15 \mathrm{~cm}$. 
The patient was rapidly resuscitated with fluids in the intensive care unit and then taken to the operating room for laparotomy. Upon induction of anesthesia, she had a cardiac arrest, from which she was resuscitated successfully. During the operative procedure, the cecum was noted to be perforated and necrotic. The right colon was resected, and a terminal ileostomy and mucous fistula of the transverse colon was fashioned.

After a prolonged postoperative course complicated by severe multisystem failure, the patient died on Sept 12 . Pathologic study of the specimen showed classic PMC (Fig 4).

\section{Case 3}

An 80-year-old woman was admitted on April 19, 1986, with a chief complaint of hematemesis. She had been in recent poor health, and had noted diffuse, non Case 3 An 80-year-old woman was admitted on April 19, 1986, with a chief complaint of hematemesis. She had been in recent poor health, and had noted diffuse, nondescript abdominal pain during the past few weeks. She had been hospitalized at another institution until three days prior to this admission for an ulcer of the left leg; her treatment there had included intravenous antibiotics.

The medical history included noninsulin-dependent diabetes mellitus, osteoarthritis, and peripheral vascular disease.

In the emergency department, she was alert and oriented but in moderate distress from abdominal pain. Her vital signs included blood pressure of $100 / 64 \mathrm{~mm} \mathrm{Hg}$, pulse rate of 88 beats per minute, and temperature of $98.6^{\circ} \mathrm{F}$. The skin was diaphoretic. Her neck was supple, with vein distention. The heart was regular, and the lungs were clear but there was poor inspiratory effort.

The patient's abdomen was morbidly obese, distended, tympanitic, and silent. There was guarding diffusely and rebound tenderness in both lower quadrants, although it localized more to the right. Rectal examination showed brown, heme-negative stool. The extremities were unremarkable.

Plain films of the abdomen disclosed dilatation of the large and small intestines, which was suggestive of colon obstruction. Chest films showed clear lung fields and an elevated right hemidiaphragm. No free air was seen on the chest or abdominal roentgenographs.

Laboratory studies of significance included a white blood cell count of $30,500 / \mathrm{cu} \mathrm{mm}$, with a differential count of $73 \%$ polymorphonuclear leukocytes, $13 \%$ band forms, $13 \%$ lymphocytes, and $1 \%$ monocytes. The platelet count was $717,000 / \mathrm{cu} \mathrm{mm}$. Urinalysis showed the presence of white blood cells too numerous to count.

In the intensive care unit, aggressive fluid resuscitation was begun. The tentative diagnosis was colon obstruction with perforation. Once the patient's condition stabilized, she was taken to surgery. Laparotomy disclosed a peritoneal cavity filled with pus. In addition to a free peritoneal abscess, she also had abscesses in the retroperitoneum, right subdiaphragmatic space, and prevesical space. The cecum was necrotic and perforated. There were inflammatory adhesions between contiguous loops of small bowel. The right colon was resected,

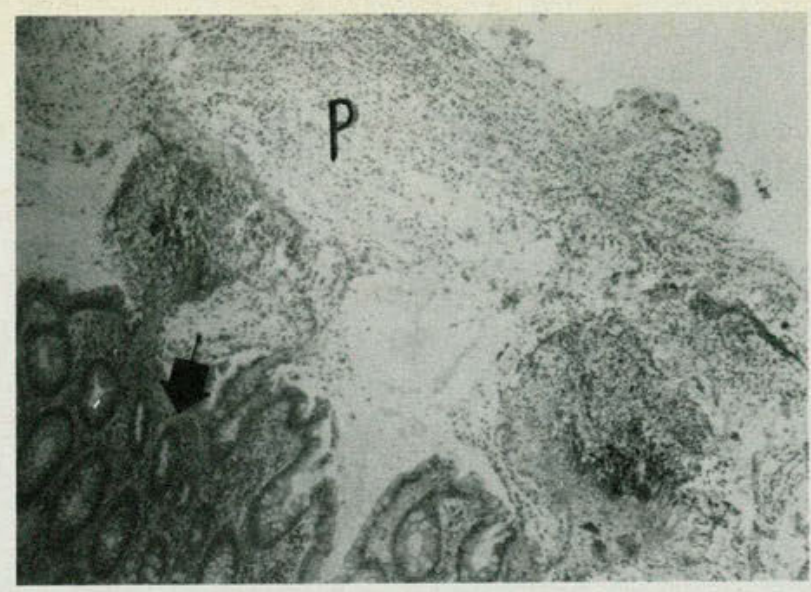

Fig 4. Section of cecum (case 2). There is disruption of the entire mucosa, with sparing only of the deep mucosal glands (arrow). The pseudomembrane $(P)$ replacing the mucosa is readily apparent (hematoxylin and eosin stain, $x 400$ magnification).

and ileotransverse colostomy was performed.

The subsequent hospital course kept worsening, and the patient died on May 5. Pathologic study of the cecum was consistent with classic PMC (Figs 5 and 6 ).

\section{Discussion}

Etiology

PMC has been shown to be caused by any number of antibiotics. The disease first was recognized by its association with clindamycin and lincomycin use. ${ }^{2}$ While clindamycin is probably the most implicated drug, Table $1^{4,7-14}$ lists those antibiotics specifically reported to cause PMC. It is thought that antibiotic administration leads to altered bowel homeostasis, which in turn allows $C$ difficile overgrowth and then PMC. ${ }^{10}$

$C$ difficile has been shown to produce a toxin that is responsible for the mucosal damage in PMC. This is neutralized in vitro by $C$ sordellii antitoxin ${ }^{6}$ and is the basis for the $C$ difficile titer determination, a laboratory study for confirming the presence of toxin in the feces.

\section{Presentation}

The earliest lesion in PMC is superficial necrosis of the mucosal surface, which occurs when glandular tubules secrete excessive amounts of mucus. The fibrinous exudate mixes with the excessive mucus, and these coalesce to form an extensive membrane-the membrane of PMC. As the disorder progresses, the membrane sloughs and leaves an ulcer that may penetrate the muscular coat. When examined endoscopically, the mucosa is edematous, has raised plaques, and is yellow in color. ${ }^{9}$ The plaques usually are 2 to $5 \mathrm{~cm}$ in size, but they can be confluent. ${ }^{15}$ 


\section{Feldene (PIROXICAM) alang}

\section{Prescribe one $20 \mathrm{mg}$ capsule daily for convenience and compliance}

Indicates maximum dosage for osteoarthritis and rheumatoid arthritis for the antiarthritic agents stiown Source: PDR, 1987, Manufacturers' Prescribing Information

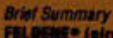

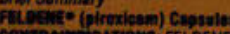

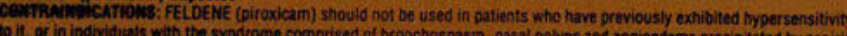
Oit. or in individuats with the synderome comprised of bronchospasm, nasal potyps and angioedema preciptated by aspirit rother nongteroidal anti-infiammatory grugs.

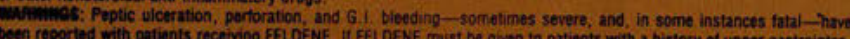
been roported with patients receiving FELDENE, If FELDENE must be given to patients with a history of upDer gastrointes tinal Iract disease, the pationt shousd be under close supervision (see ADVEASE REACTIONS).

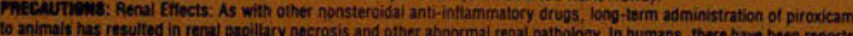

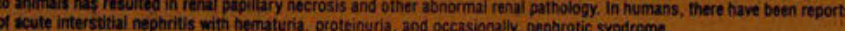

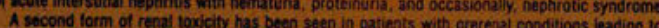

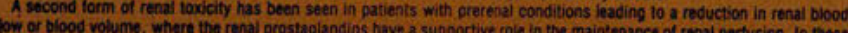

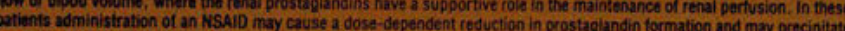
cyert resai decompensation. Patents at greatest risk of this reaction are those with impaired renal function, heart tailure. iver dystunction, those taking diuretics, and ine elderty

Because of gxtensive renal excretion of pirexicam and its biotranstormation products liess than $5 \%$ of the daily dose

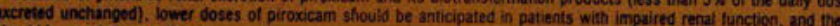
should be carelulily monitored

Atthouph other nonsteroical antl-inflammatory drugs do not have the same direct ettect on platedets that aspirin does

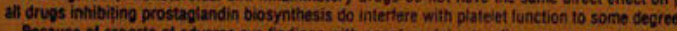

Beccusse of reporis of zdverse eye findings with nonsteroddal antl-intlammatory agents, it is iecommended that patients Who develop visual compiaints during treatinent with FELDENE have ophthaimic evaluation.

As with other nonstercideal antit-inflammatory drugs. borderline elevations of one or more ilver tests may occur in ug to $15 \%$ of patients. A pationt with symptoms andior signs sugpesting fiver dystunction, or in whom abnormal liver lests navi oceurres. should be emaluatiod tor evidence of the develogment of more severe hepastic reaction while on therapy with

Severe tepatic reactions, Including jaundice and cases of tatai hegatitis have been reported with FELDENE. Atthought such reactions are rare, it abnormai liver tests persist or worsen, if ciinical sions and symptoms consistent with liver fis

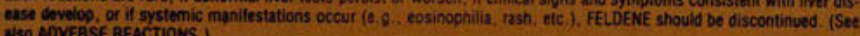

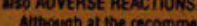

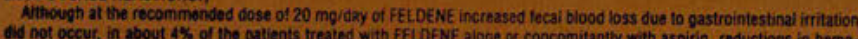
div not occurt in about 4\% of the patients treased with FEL OENE alone or concomitantly with aspirin, reductions in hemopooin and hematocit values were observed

Peripheral esemas nas been observed in approximatety 26 of the patents itrated with FELDENE. Theretore. FELDENF A combination of caviton in pastients with heart taiture, hypertension or other conditions predisposing lo fluid retention. $A$ combination of dermatolopical ancor a allergic sions and symptoms suggestive of serum sickness have oecasionalif occurreo in conjunctoon with the use ot FELDENE, These include arthiafoias, pruntus, tever, tatigue, and rash including

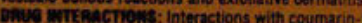

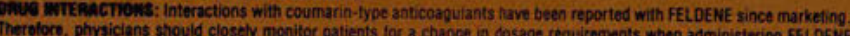
Detior patients for a change in cosage requiroments when administering FEL DENF wo partents on coumarin-type anticoagulants ano other highly protein-bound drups.

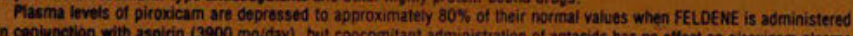
in conis

Monsteroidar ant-infiammatory sgents, inciuding FELDENE, have been reported to increase steady state plasma lithium

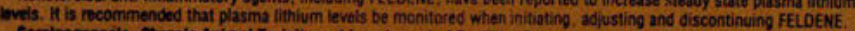

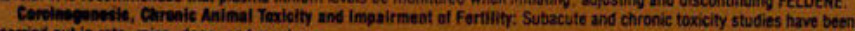
carried out in rats, mico, dogs, and monkeys

The pathology most onten seen was that charactenisticaliy associnted with the animal toxicology of anti-inflammatory agents: real papitary neccosis (see PRECAUTioNS) and gastrointestinal lesions

In classical studies in laboratory animais, piroxicam dic nol stow any teratogenic potential.

Reproductive studies rovealed no impairment of fertiity in animals

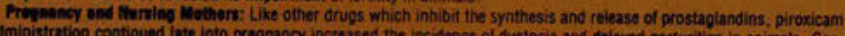
administration continued late into pregnancy increased the incidence of dystocia and delayed parturition in animals. Gas. trointestinal tract toxicity was increased in pregnant temales in the last trimester of pregnancy compared to non-pregnant femaus or iemales in eariler trimesters of pregnang)

FEL DENE is not recommendeo tor use in nursing mathers or in pregnant women because of the anima findings and since alfoy for such use has not been estabished in humans

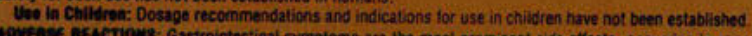

AOVEnse nEACnows: Gastrointestinal symptoms are the most prominent side etfects, occurring in approximately $20 \%$ of me patients, which in most instances did not intertere with the course of therapy of the patients experiencing gastr:

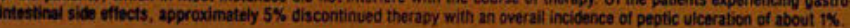

Adverse reactions are listed below by body system for all patients in clinical trials with FELOENE (oiroxicam) at doses of $20 \mathrm{mg} /$ day.

lacidenca Groatec Than 1\%: The following adverse reactions occurred more frequently than 1 in 100

Gastrointastinat stomattis, anorexia, eplgastric distress; nausea; constipation, aboominal discomfort, natulence. diarmea, abdominal pain, indigestion

Memutobgicat: decreases in hemoglooin' and hematocrit' (sae PAECAUTIONS), anemia, levcopenia, eosinophalia Denmatolopic: prunitus, rash

Sentral Nervous System diziness, somnolence, vertip

Urogontal: BUN and creatinine elevations (see PRECAUTIONS)

hocy as a Whole: headache, maiais?

Spedial Senses: tinnitus

Cindionascular:Respiratory: edema (see PRECAUTIONS)

Reactions occurring in $3 \%$ to $9 \%$ of patients treated with FELOENE. Reactions occurring in $1 \%$ to $3 \%$ of pationts art

Incldence Leas Than $1 \%$ (Causal Relationship Probable): The following adverse reactions occurred less frequently than 1 in 100. The probability exists that there is a causal relationship between fELLENE and these reactions

Gastrointestinas: Iver function abnormalities, jaundice, hepatitis (see PAECAUTIONS), vomiting, hematemesis, melena pastrointestinal bleeding. pertoration and wicaration (see wheviNGS) dry moith

Hemetologicat: thrombocytopenia, petechial rash, ecchymosis, bone mantow depression including aptastic anemia pistaxis

Dermatologic: sweating, erytherna, bruising, desquamation, extoliative dermatitis, erythema multiforme, foxic egider mal necrolysis, Stevens vohnson synarome, vesiculo buflous reactions, photoallergic skin reactions

Central Nervous System: depression. insomnia, nerupusnese

Urogenital: hematuria, proteinuria, interstitial nephritis, renal failure, hyperkaiemia, olomerulitis, papiliary necrosis, epharotic synarome (seo PRECAUTIONS

socy as a Whole: pain (colic), fever, flu-like syndrome (see PRECAUTIONS)

Cardiovesculari Respiratory tryeertension, worsening of congestive heart failure (see PRECAUTIONS), exacorthotion of anpina

Metabolic: hypoglycemia, typerglycemia, weight inctease, weight decrease

Hypersensitivity; anaphylaxis, bronchospasm, urticarianangloedema, vascultis, 'serum sickness' ( Ineloence Less man 1\% (Gausal Relationsnip Unknown): Other adverse reactions were reported with a frequency of less than 1 in 100, but a causal relationship between FEL DENE and the reaction could not be determineo

Gastrointestinat: pancreatitis

Darmatologic: onycholysis, loss of hair

Central Nervous System: akathisia, hallucinations, mood alterations, dream abnormalities. mental confusion. aresthesias

Urogenital System: dysuria

coory as a Whole weakness
Cardiovascular fiespiratory palpitations, dyspnet

Hypersensitivily: positive ANA

Spocial Senses: hearing impaiment

Special Senses: hearng impaiment

OVERDOSAGE: In the tvent treatment for overdosage is required. the long plasma half-iffe of piroxicam should be consi. ered. The absence of experience with acute overdosape precludes characterization of sequelae and recommendations of specilic antiotal efficacy at this time. It is reasonabie to assume that the standard measures of gastric evacuation and general supportive therapy would apply. In addition to supportive measures, the use of activated charcoal may etlectively reduce the absorption and reabsorption of piroxicam. Experiments in doos have demonstrated that the use of multiple-dose treatments with activatod charcosi could reduce the halt-ilfe of piroxicam elimination from 27 hours (without charcoal) to If hours and reduce the systemic bioavailability of piroxicam by as much as $37 \%$ when activated charcoal is given as late us 6 hours ather administration of piroxicam

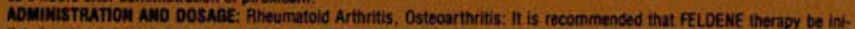
bated and maintained at a single daily dose of $20 \mathrm{mQ}$. If desired, the daily dose may be divided

Dusape recommendations and indications for use in children have not been establiched.

O1982. Pfizet Inc Revised May 1988 


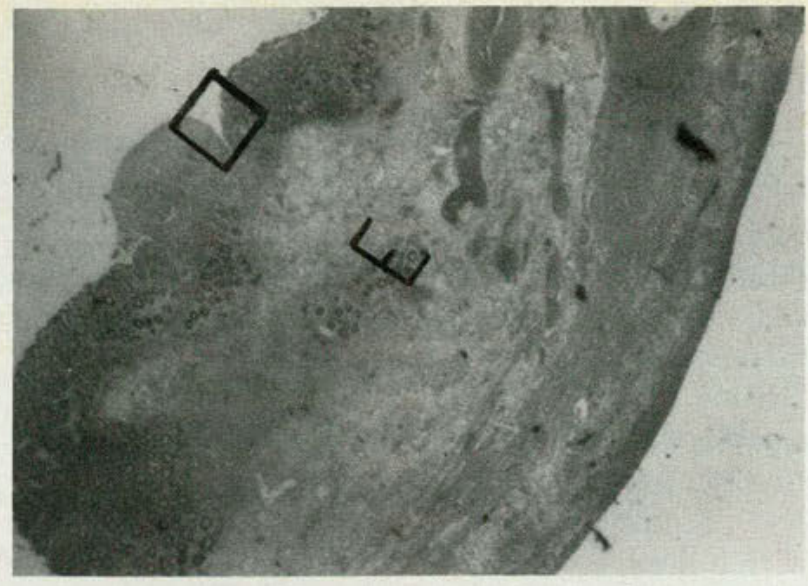

Fig 5. Section of cecum (case 3). The area of maximal involvement is well demarcated from adjacent bowel. There is profound submucosal edema (E) (hematoxylin and eosin stain, $x 100$ magnification).

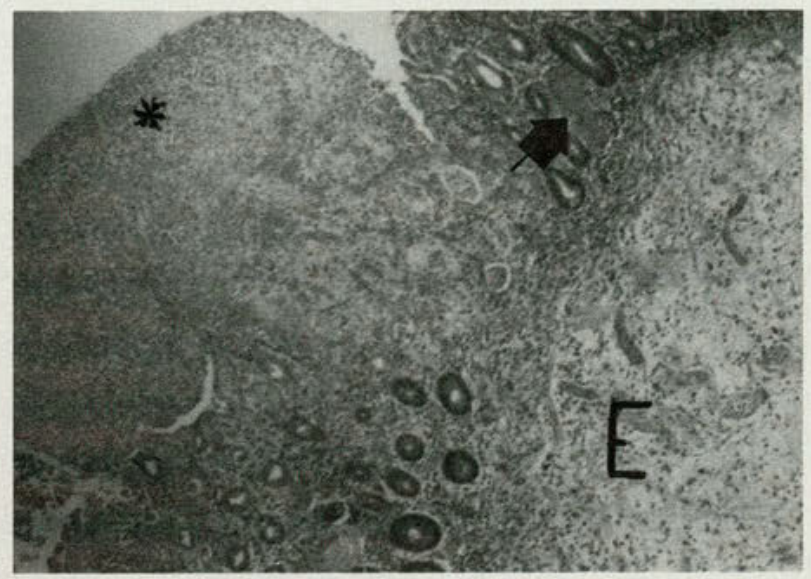

Fig 6. Enlargement of the area in Fig 5 (case 3). The mucosal section retains normal architecture, but demonstrates vascular congestion (arrow), adjacent to an area with total disruption of the mucosa (asterisk). Submucosal edema (E) again is demonstrated (hematoxylin and eosin stain, $x 400$ magnification).

In patients who develop toxic megacolon, pathologic study of the colon shows profound mural edema, which is thought to be caused by the toxin effect on the mucosa combined with fluid resuscitation. ${ }^{15}$ In later stages of PMC, the appearance of the bowel is similar to that of ischemic colitis. The fact that ischemic disease tends to be segmental and is not associated with the massive mural edema found in PMC aids in differentiation. ${ }^{15}$

There is a female:male ratio of $2.2: 1$ and a mean age of 54 years in PMC. ${ }^{12}$ The disease can present in one of two ways: Patients who develop PMC while taking antibiotics usually manifest a selflimiting form, one that usually is responsive to discontinuation of the medication. Those who develop PMC days to weeks after the antibiotic is stopped, or while taking antibiotics with continuation of the drug, usually manifest massive watery diarrhea, bloody stool, electrolyte imbalance, and albumin loss. ${ }^{4}$

Table 2 differentiates between the characteristics of early onset stools and late onset diarrhea. ${ }^{1,16}$ Table 3 shows the more common symptoms of PMC on presentation. ${ }^{17}$

On very rare occasions, PMC progresses to toxic megacolon and can go on to perforation. The extreme rarity of this complication is pointed out by Snooks and coworkers, ${ }^{7}$ who in 1984 found no reported cases in a review of 66 patients with PMC. Since then, a number of case reports ${ }^{6,7,10,15,18,19}$ of patients who were quite ill and receiving antibiotics who developed colonic dilatation, some of whom went on to develop perforation and fecal peritonitis, have appeared in the literature. Diagnostic criteria of toxic megacolon are "acute dilatation of all or part of the colon to a diameter greater than $6 \mathrm{~cm}$ with associated systemic toxicity." 18 Toxic megacolon seems to occur with the same male:female ratio and mean age as uncomplicated PMC. ${ }^{12}$

\section{Diagnosis}

For stable patients, or for patients who have a confusing clinical picture, a variety of imaging techniques can assist in diagnosis. Plain roentgenographs obtained from patients with PMC can show mild, diffuse small bowel dilatation, thumbprinting of the colon, haustral thickening, ascites, and colonic dilatation. ${ }^{20}$

When the patient is stable and no risk of perforation or toxicity exists, double-contrast barium enema can be helpful. The pseudomembranes appear as filling defects a few millimeters apart; at times, they are confluent. The mucosa appears edematous, without ulceration. ${ }^{9}$ Ultrasonography displays

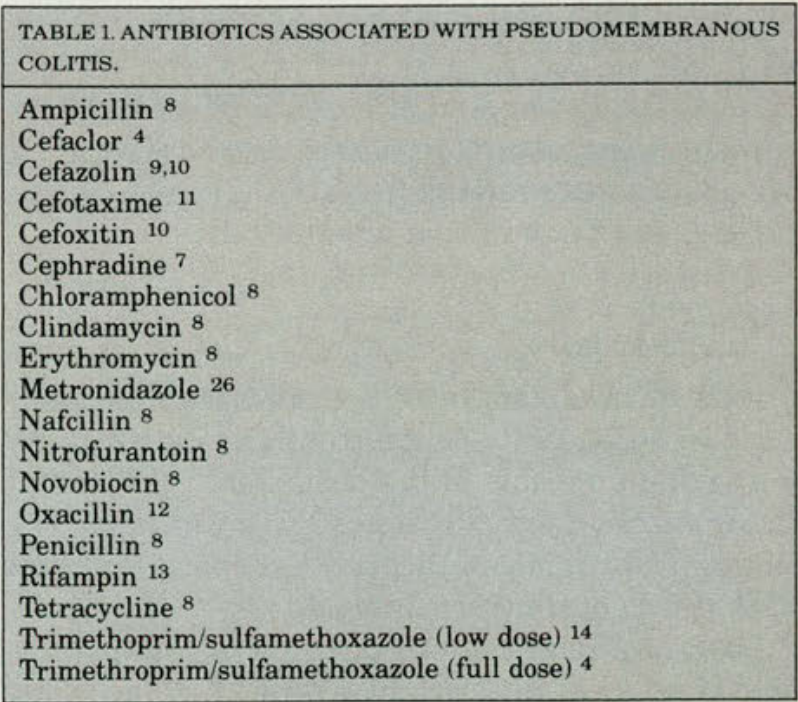


marked dilatation of the bowel loops with air, thickened, edematous bowel walls, and small amounts of free intraperitoneal fluid. ${ }^{21}$

While computed tomography (CT) is not part of a workup for diarrhea, many times PMC presents with symptoms suggestive of extracolonic disease, sach as intra-abdominal abscess. If PMC is present, CT will demonstrate a thickened and edematous colon wall, and thumbprinting may be apparent. ${ }^{22-24}$ While gallium scanning would be of no use in the acute setting, it has been shown that it can demonstrate persistent activity in the area of PMC up to 96 hours before the clinical appearance of the disease. This could be useful in difficult cases, for follow-up, and to help diagnose relapses. ${ }^{25}$

Diagnosis of PMC usually rests either on confirmation of the presence of $C$ difficile in the feces (by culture or toxin assay) or on endoscopic evidence of pseudomembranes. The most commonly performed procedure to confirm the latter is rigid sigmoidoscopy. However, studies have shown that the pseudomembranes may be located above the $25-\mathrm{cm}$ limit of the rigid sigmoidoscope. ${ }^{9}$ One study, ${ }^{4}$ which was undertaken to determine the significance of rectal sparing, demonstrated that $77.3 \%$ of patients with PMC had pseudomembranes within $25 \mathrm{~cm}$ from the anus (within the range of the rigid sigmoidoscope), $90.9 \%$ had pseudomembranes within $60 \mathrm{~cm}$ of the anus (within the range of the flexible sigmoidoscope), and $9.1 \%$ had pseudomembranes more than $60 \mathrm{~cm}$ from the anus (only within the range of the colonoscope). These findings suggest that if sigmoidoscopy is negative and the clinical suspicion points to PMC, the physician should proceed with colonoscopy or culture or toxin titer tests.

Using selective medium (cycloserine cefoxitin fructose agar), $C$ difficile can be cultured. The absence of organisms would be a reliable negative result. ${ }^{2}$ However, the presence of $C$ difficile bacteria in culture does not confirm the presence of PMC, because there are rare patients who harbor the organism as asymptomatic carriers. ${ }^{8}$ Therefore, it is considered more reliable to perform the $C$ difficile toxin assay as definitive proof of PMC.

\section{Treatment}

Successful PMC therapy involves eradication of the $C$ difficile organism from the colon with antibiotics, and, secondarily, binding of the toxin using anion exchange resins. If the bacterium is killed but the toxin remains, the disease will continue. The therapy for uncomplicated ${ }^{4,26}$ and recurrent PMC $^{27,28}$ is outlined in Table 4.

Vancomycin is the mainstay of antibiotic therapy. It is generally used at a dose of 500 to 2,000 mg daily in four divided oral doses. ${ }^{4,26}$ When the patient's condition prohibits oral medication, vancomycin can be delivered as a retention enema in a dosage of $1 \mathrm{~g} / 1,000 \mathrm{cc}$ of saline solution every 6 h. ${ }^{29}$ This drug is effective against all strains of $C$ difficile and attains fecal levels of 25 to 200 times its minimum inhibitory concentration (MIC). The drug of second choice is metronidazole 4 . The regimen is 1.2 to $1.5 \mathrm{~g} /$ day in divided oral doses. ${ }^{26} \mathrm{Un}$ fortunately, there have been case reports of this agent causing PMC; also, it is well absorbed in the small bowel, which leads to questionable fecal levels. ${ }^{26}$ Finally, bacitracin has been used for PMC, with a dosage of 25,000 units four times a day. ${ }^{26}$

The anion exchange resins used for the treatment of PMC are cholestyramine ${ }^{30}$ and cholestipol. ${ }^{17}$ These reversibly bind the $C$ difficile toxin; either is given at a dose of $4 \mathrm{~g}$ orally three times daily. ${ }^{4}$ Antiperistaltic agents should not be used, because they can worsen or prolong the course of the disease. ${ }^{26}$

While vancomycin is almost always successful in treating PMC, recurrence rates as high as $14 \%$ have been reported. ${ }^{27}$ The two possible etiologies of recurrence are spore formation by the $C$ difficile organism and environmental reinfection. ${ }^{27}$ Various regimens have been suggested to treat these relapses. These range from a five-week course of oral vancomycin ${ }^{30}$ to a prolonged course of cholestyramine ${ }^{30}$ to a tapering dosage schedule of vancomycin and cholestipol. ${ }^{27}$

Because of the possibility of environmental crosscontamination, patients with PMC should be isolated. Contamination can come from hospital personnel or inanimate objects. The organism can survive on a hospital floor for up to five months. ${ }^{31}$

Once pseudomembranous colitis progresses to

\begin{tabular}{|lcc|}
\hline $\begin{array}{l}\text { TABLE 2. CHARACTERISTICS OF STOOLS OF } \\
\text { (ADAPTED FROM MILLER AND ASSOCIATES). }\end{array}$ & \\
\hline Parameter & Early onset & Late onset \\
\hline No. of patients & 34 & 6 \\
No. of stools/day & 5 & 5 \\
Stool consistency & Watery & Soft, bulky \\
Mucus in stool & 30 & 6 \\
Blood in stool & 4 & 0 \\
\hline
\end{tabular}

\begin{tabular}{|c|c|}
\hline Presentation & Frequency $(\%)$ \\
\hline Water diarrhea & $90-95$ \\
\hline Bloody diarrhea & $5-10$ \\
\hline Crampy abdominal pain & $80-90$ \\
\hline Fever $\left(100^{\circ} \mathrm{F}-104^{\circ} \mathrm{F}\right)$ & 80 \\
\hline Leukocytosis & 80 \\
\hline Rebound tenderness & $10-20$ \\
\hline
\end{tabular}


TABLE 4. PMC THERAPY.

\begin{tabular}{|c|c|c|}
\hline Agent & Dosage & Route \\
\hline \multicolumn{3}{|c|}{ Uncomplicated PMC } \\
\hline \multicolumn{3}{|l|}{ Antibiotics 4, 26} \\
\hline Vancomycin & $500-2,000 \mathrm{mg} /$ day & oral, ${ }^{16}$ enema $^{29}$ \\
\hline Metronidazole & $1.2-1.5 \mathrm{~g} /$ day & oral \\
\hline Bacitracin & $\begin{array}{l}25,000 \text { units four } \\
\text { times daily }\end{array}$ & oral \\
\hline \multicolumn{3}{|c|}{ Anion exchange resins 19} \\
\hline Cholestyramine & $\begin{array}{l}4 \mathrm{~g} \text { three times } \\
\text { daily }\end{array}$ & oral \\
\hline Cholestipol & $\begin{array}{l}4 \mathrm{~g} \text { three times } \\
\text { daily }\end{array}$ & oral \\
\hline
\end{tabular}

\section{Recurrent PMC}

Schedule 129

Vancomycin $125 \mathrm{mg}$ every $6 \mathrm{~h}$ for seven days, or

Vancomycin $125 \mathrm{mg}$ daily plus cholestipol 5 g every $12 \mathrm{~h}$ for five to seven days, or

Vancomycin $125 \mathrm{mg}$ plus cholestipol $5 \mathrm{~g}$ every $12 \mathrm{~h}$ for five to seven days, or

Cholestipol 5 gm every $12 \mathrm{~h}$ for 14 days

Schedule $2{ }^{30}$

Vancomycin $125 \mathrm{mg}$ every $6 \mathrm{~h}$ for seven days, or

Vancomycin $125 \mathrm{mg}$ every $12 \mathrm{~h}$ for seven days, or

Vancomycin $125 \mathrm{mg}$ once daily for seven days, or

Vancomycin $125 \mathrm{mg}$ every other day for seven days, or

Vancomycin $125 \mathrm{mg}$ every third day for 14 days

the point of perforation and acute abdomen, aggressive surgical management is indicated. Our three patients died as a result of colonic perforation with resultant sepsis and multisystem failure. If an aggressive surgical management posture is undertaken and patients are seen prior to perforation, perhaps the outcome can be improved.

\section{Summary}

Pseudomembranous colitis occurs when there is a bacterial overgrowth of $C$ difficule in the colon, usually, but not always, from antibiotic use. The severity of the disease can range from mild, selflimited diarrhea to fulminant toxic megacolon with perforation, and the treatment can vary from simple discontinuation of the offending antibiotic to colon resection for perforation. We reported three patients who presented with colonic perforation secondary to PMC and described the diagnosis and treatment and recurrent PMC.

\footnotetext{
1. Moskovitz M, Bartlett JG: Recurrent pseudomembranous colitis unassociated with prior antibiotic therapy. Arch Intern Med 1981;141:663664.

2. Griebie M, Adams GL: Clostridium difficile colitis following head and neck surgery: Report of cases. Arch Otolaryngol 1985;111:550-553.

3. O'Connor TW: Pseudomembranous enterocolitis: A historical and clinical review. Dis Colon Rectum 1981;24:445-448.

4. Tedesco FJ, Corless JK, Brownstein RE: Rectal sparing in antibiotic-
}

associated pseudomembranous colitis: A prospective study. Gastroenterology 1982;83:1259-1260.

5. Bartlett JG: Antibiotic-associated pseudomembranous colitis. Hosp Pract 1981;2:85-95.

6. Templeton JL: Toxic megacolon complicating pseudomembranous colitis. Br J Surg 1983;70:48.

7. Snooks SJ, Hughes A, Horsburgh AG: Perforated colon complicating pseudomembranous colitis. Br J Surg 1984;71:291-292.

8. George WL, Rolfe RD, Harding GK, et al: Clostridium difficile and its cytotoxin in feces of patients with antimicrobial agent-associated pseudomembranous colitis. Infection 1982;10:205-208.

9. Strada M, Meregaglia D, Donzelli R: Double-contrast enema in antibiotic-related pseudomembranous colitis. Gastrointest Radiol 1983;8:6769.

10. Osler T, Lott D, Bordley J IV, et al: Cefazolin-induced pseudomembranous colitis resulting in perforation of the sigmoid colon. Dis Colon Rectum 1986;29:140-143.

11. Nolan N, Tighe B, Cooney C, et al: Cefotaxime and pseudomembranous colitis, letter. Lancet 1985;2:888.

12. Thomas E, Mehta JB: Pseudomembranous colitis due to oxacillin therapy. South Med J 1984;77:532-533.

13. Fekety R, O'Connor R, Silva J: Rifampin and pseudomembranous colitis. Rev Infect Dis 1983;5(suppl 3):S524-S527.

14. Ruff D, Jaffe J, London R, et al: Pseudomembranous colitis following low dose trimethoprim-sulfamethoxazole. J Urol 1985;134:1218-1219.

15. Schnitt SJ, Antonioli DA, Goldman H: Massive mural edema in severe pseudomembranous colitis. Arch Pathol Lab Med 1983;107:211213.

16. Miller SD, Blake M, Miliotis M, et al: Antibiotic-associated diarrhea and pseudomembranous colitis caused by Clostridium difficile: A review of 40 cases. S Afr Med J 1983;63:936-939.

17. Tedesco FJ, Napier J, Gamble W, et al: Pseudomembranous colitis: Pathogenesis and treatment. Med Clin North Am 1982;66:655-664.

18. Cone JB, Wetzel W: Toxic megacolon secondary to pseudomembranous colitis. Dis Colon Rectum 1982;25:478-482.

19. Klinger D, Radford P, Callin J: Pneumoperitoneum without fecal peritonitis in a patient with pseudomembranous colitis. $\mathrm{Br} \mathrm{Med} J$ $1984 ; 288: 1271-1272$.

20. Loughran CF, Tappin JA, Whitehouse GH: The plain abdominal radiograph in pseudomembranous colitis due to Clostridium difficile. Clin Radiol 1982;33:277-281.

21. Bolondi L, Ferrentino M, Trevisiani F, et al: Sonographic appearance of pseudomembranous colitis. J Ultrasound Med 1985;4:489-492. 22. Goodman PC, Federle MP: Pseudomembranous colitis. J Comput As sist Tomogr 1980;4:403-404.

23. Brunner D, Feifarek C, McNeely D, et al: CT of pseudomembranous colitis. Gastrointest Radiol 1984;9:73-75.

24. Megibow AJ, Streiter ML, Balthazar EJ, et al: Pseudomembranous colitis: Diagnosis by computed tomography. $J$ Comput Assist Tomogr 1984;8:281-283.

25. Kramer EL, Charap M, Sanger JJ, et al: Pseudomembranous colitis: A possible role for gallium scanning. Am J Gastroenterol 1983;78:632633.

26. Gross MH: Management of antibiotic-associated pseudomembranous colitis. Clin Pharm 1985;4:304-310.

27. Tedesco FJ: Treatment of recurrent antibiotic-associated pseudomembranous colitis. Am J Gastroenterol 1982;77:220-221.

28. Tedesco FJ, Gordon D, Fortson WC: Approach to patients with multiple relapses of antibiotic-associated pseudomembranous colitis. Am J Gastroenterol 1985;80:867-868.

29. Goodpasture HC, Dolan PJ, Jacobs ER, et al: Kans Med 1986;87:133, 146.

30. Kunimoto D, Thomson AB: Recurrent Clostridium difficile-associated colitis responding to cholestyramine. Digestion 1986;33:225-228.

31. Shortland JR, Spencer RC, Williams JL: Pseudomembranous colitis associated with changes in a ileal conduit. J Clin Pathol 1983;36:11841187.

From the Department of Surgery (all authors) and Surgery and Vascular Surgery (Dr Feinman), Metropolitan Hospital, Parkview Division, Philadelphia.

Reprint requests to Dr Feinman, Suite A-01, 1331 E Wyoming Ave, Philadelphia 19124. 


\section{NEW300 mg CAPSULES}




\section{FOR SERIOUS INFECTIONS}

\section{Clinically effective in serious polymicrobial}

infections involving Bacteroides fragilis and other important anaerobes, staphylococci, streptococci, and pneumococci. Follow-up therapy to CLEOCINIV, or initial therapy when clinically appropriate.

Positive penetration profile. $\mathrm{CLEOCINHCl}$ is rapidly and predictably absorbed, rapidly penetrates most body tissues and fluids, including bone and pus. Food does not significantly affect absorption.

Not a beta-lactam. No cross-allergenicity with penicillins or cephalosporins. However, maculopapular rash and urticaria have been observed during therapy with CLEOCIN.

CLEOCIN is generally well tolerated. Like many other antibiotics, however, it has been associated with Clostridium difficile colitis. Available evidence does not suggest a relationship to dosage or route of administration.

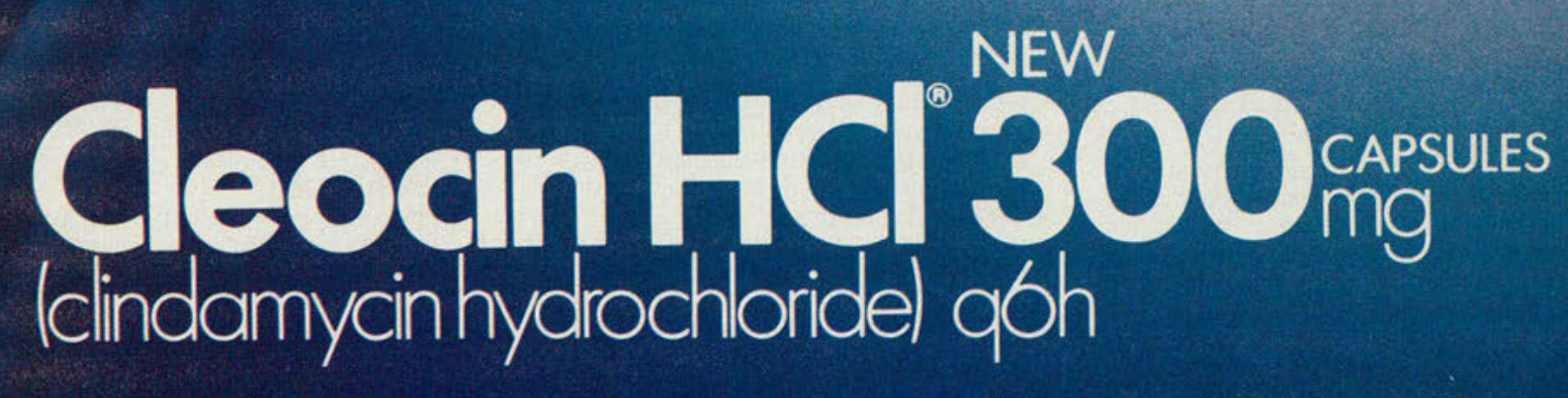

Please see adjacent page for brief summary of prescribing information.

\section{Upjohn}




\section{FOR SERIOUS INFECTIONS: NEW Cleocin HCl 300 imars}

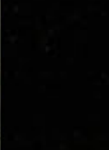

CLEOCINPHOSPHATE ${ }^{\circledast}$ Sterile Solution CLEOCIN HCl ${ }^{\circ}$ Capsules (clindamycin)

\section{WARNING}

Clindamycin therapy has been associated with severe colitis which may end fatally. Therefore, it should be reserved for serious infections where less toxic antimicrobial agents are inap propriate, as described in the Indications Section. It should not be used in patients with nonbacterial infections, such as most upper respiratory tract infections. Studles indicate a toxin(s) produced by Clostridia is one primary cause of antibiotic associated colitis.

Cholestyramine and colestipol resins have been shown to bind the toxin in vitro. See WARNINGS section. The colitis is usually characterized by severe, persistent diarrhea and severe abdominal cramps and may be associated with the passage of blood and mucus. Endoscopic examination may reveal pseudomembranous colitis. Stool culture for Clostridium difficile and stool assay for

C. difficile toxin may be helpful diagnostically. When significant diarrhea occurs, the drug should be discontinued or, if necessary. continued only with close observation of the patient. Large bowel endoscopy has been recommended

Antiperistaltic agents such as opiates and diphenoxylate with atropine (Lomotil) may prolong and/or worsen the condition. Vancomycin has been found to be effective in the treatment of antibiotic associated pseudomembranous colitis produced by Clostridium difficile. The usual adult dose is 500 milligrams to 2 grams of vancomycin orally per day in three to four divided doses administered for 7 to 10 days. Cholestyramine or colestipol resins bind vancomycin in vitro. If both a resin and vancomycin are to be administered concurrently, it may be advisable to separate the time of administration of each drug.

Diarrhea, colitis, and pseudomembranous colitis have been observed to begin up to several weeks following cessation of therapy with clindamycin.

\section{INDICATIONS}

Serious infections caused by susceptible anaerobic bacteria. Patients with serious infections due to susceptible strains of streptococci, pneumococci, and staphylococci in whom its use should be reserved for penicillin-allergic patients or other patients for whom, in the judgment of the physician, a penicillin is inappropriate

Consider the nature of the infection and the suitability of less toxic alternatives (e.g., erythro mycin). Bacteriologic studies should be performed to determine the causative organisms and their susceptibility to clindamycin

\section{CONTRAINDICATIONS}

History of hypersensitivity to clindamycin or lincomycin.

\section{WARNINGS}

See WARNING box. A toxin produced by Clostridia is one primary cause of antibiotic associated colitis. Cholestyramine and colestipol resins have been shown to bind the toxin in vitro. Mild cases of colitis may respond to drug discontinuance alone. Moderate to severe cases should be managed promptly with fluid, electrolyte and protein supplementation as indicated. Vancomycin has been found to be effective in the treatment of antibiotic associated pseudomembranous colitis produced by C. difficile. The usual adult dosage is $500 \mathrm{mg}$ to 2 grams of vancomycin orally per day in 3 or 4 divided doses for 7 to 10 days. Systemic corticoids and corticoid retention enemas may help relieve the colitis. Other causes of colitis should also be considered

A careful inquiry should be made concerning previous sensitivities to drugs and other allergens. Usage in Pregnancy: Safety has not been established. Usage in Newborns and Infants: Appropriate monitoring of organ system functions is desirable. CLEOCIN PHOSPHATE contains benzyl alcohol which has been associated with a fatal gasping syndrome in infants. Nursing Mothers: Clindamycin has been reported to appear in breast milk in ranges of 0.7 to $3.8 \mathrm{mcg} / \mathrm{ml}$. Usage in Meningitis: Since clindamycin does not diffuse adequately into the cerebrospinal fluid, it should not be used to treat meningitis.

Antagonism has been demonstrated between clindamycin and ery thromycin in vitro. Because of possible clinical significance, these two drugs should not be administered concurrently.

SERIOUS ANAPHYLACTOID REACTIONS REQUIRE IMMEDIATE EMERGENCY TREAT MENT WITH EPINEPHRINE. OXYGEN AND INTRAVENOUS CORTICOSTEROIDS SHOULD ALSO BE ADMINISTERED AS INDICATED.

\section{PRECAUTIONS}

Older patients with associated severe illness may tolerate diarrhea less well. When clindamycin is indicated in these patients, they should be carefully monitored for change in bowel frequency. Prescribe with caution in individuals with a history of gastrointestinal disease particularly colitis and also in atopic individuals. Indicated surgical procedures should be performed in conjunction with therapy. Patients with very severe renal and/or hepatic disease accompanied by severe metabolic aberrations should be dosed with caution and serum clindamycin levels monitored during high dose therapy.

During prolonged therapy, periodic liver, and kidney function tests and blood counts should be performed. Use may result in overgrowth of nonsusceptible organisms, particularly yeasts. Clindamycin has neuromuscular blocking properties and may enhance other neuromuscular blocking agents. Use with caution in patients receiving such agents. Do not inject clindamycin IV undiluted as a bolus. Dilute prior to IV administration to $300 \mathrm{mg}$ per $50 \mathrm{ml}$ or more of diluent. Infuse over at least 10-60 minutes. (See Dosage and Administration.) CLEOCIN HCl Capsules $75 \mathrm{mg}$ and $150 \mathrm{mg}$ contain FD\&C Yellow No. 5 (tartrazine) which may cause allergic-type reactions (including bronchial asthma) in certain susceptible individuals, especially in patients who also have aspirin hypersensitivity.

\section{ADVERSE REACTIONS}

Gastrointestinal: Abdominal pain, nausea, vomiting and diarrhea. (See WARNING box. An unpleasant or metallic taste has been reported with high doses.

Hypersensitivity Reactions: Maculopapular rash and urticaria. Generalized mild to moderate morbilliform-like skin rashes are the most frequent adverse reactions. Rare instances of erythema multiforme, some resembling Stevens-Johnson syndrome, have been reported. A few cases of anaphylactoid reactions have been reported. If a hypersensitivity reaction occurs, the drug should be discontinued. The usual agents should be available for emergency treatment. Liver: Jaundice and abnormalities in liver function tests have been observed. Hematopoietic: Neutropenia, eosinophilia, agranulocytosis and thrombocytopenia have been reported; no direct etiologic relationship to concurrent clindamycin therapy has been made. Local Reactions: Pain, induration and sterile abscess have been reported after intramuscular injection and thrombophlebitis after intravenous infusion. Reactions can be minimized or avoided by giving deep intramuscular injections and avoiding prolonged use of indwelling intravenous catheters. Musculoskeletal: Rare instances of polyarthritis have been reported. Cardiovascular: Rare instances of cardiopulmonary arrest and hypotension have been reported following too rapid IV infusion. (See Dosage and Administration.) Renal: Renal dysfunction with azotemia, oliguria, proteinuria has rarely been observed. No direct relationship has been established.

\section{DIRECTIONS FOR DISPENSING}

Pharmacy Bulk Package-Not for Direct Infusion The Pharmacy Bulk Package is for use in a Pharmacy Admixture Service only under a lam. inar flow hood. Entry into the vial should be made with a small diameter sterile transfer set or other small diameter sterile dispensing device, and contents dispensed in aliquots using aseptic technique. Multiple entries with a needle and syringe are not recommended. AFTER ENTRY USE ENTIRE CONTENTS OF VIAL PROMPTLY. ANY UNUSED PORTION MUST BE DISCARDED WITHIN 24 HOURS AFTER INITIAL ENTRY.

\section{HOW SUPPLIED}

Available as sterile solution with each $\mathrm{m}$ containing clindamycin phosphate equivalent to $150 \mathrm{mg}$ clindamycin base. Vials of 2, 4, and $6 \mathrm{ml}$. Vials of $600 \mathrm{mg}$ and $900 \mathrm{mg}$ are available in

ADD-Vantage ${ }^{\text {tw }}$ Vial system.

$1.60 \mathrm{ml}$ Pharmacy Bulk Package

CLEOCIN HCl as $75 \mathrm{mg}, 150 \mathrm{mg}$, and $300 \mathrm{mg}$ capsules.

Caution: Federal law prohibits dispensing without prescription.

$A D D$-Vantage is a registered trademark of Abbott Laboratories.

For additional product information see your Upjohn representative.

Upjohn 